\title{
ANALISIS MEDAN KEKUATAN TERHADAP BARAPAN KEBO SEBAGAI ATRAKSI COMMUNITY BASED TOURISM (CBT) DI KABUPATEN SUMBAWA BARAT Force Field Analysis on Barapan Kebo as Community Based Tourism (CBT) Attraction in West Sumbawa Regency
}

\author{
Amir Ma'ruf \\ Fakultas Ekonomi Universitas Cordova \\ Taliwang Sumbawa Barat NTB
}

Diterima: 12 Juni 2020. Disetujui: 06 Juli 2020. Dipublikasikan: 07 Juli 2020

\begin{abstract}
Abstrak
Pariwisata berbasis masyarakat atau Community Based Tourism (CBT) merupakan konsep pengelolaan pariwisata yang menjanjikan manfaat maksimal bagi masyarakat, menjadikan pariwisata inklusif bagi masyarakat, dan lebih menjamin keberlanjutan pariwisata sendiri. Atraksi wisata yang paling mungkin dikelola ala CBT adalah wisata budaya yang memiliki banyak atraksi yang digemari para wisatawan saat ini. Dalam pada itu, Barapan kebo merupakan permainan rakyat yang secara rutin diselenggarakan oleh masyarakat di Pulau Sumbawa. Kajian ini bertujuan untuk mengidentifikasi kesesuaian barapan kebo untuk dijadikan daya tarik wisata berbasis masyarakat dan menganalisis langkah strategis apa yang perlu dilakukan untuk menjadikan barapan kebo sebagai daya tarik wisata berbasis masyarakat. Alat yang digunakan adalah AMK. Hasilnya menunjukkan bahwa Barapan Kebo layak dijadikan daya tarik wisata berbasis masyarakat dan Faktor Kunci Keberhasilan (FKK) pendorongnya adalah kecenderungan wisatawana terhadap budaya yang unik dan FKK penghambatnya adalah belum dipasarkannya Barapan Kebo sebagai daya tarik wisata. Opsi langkah strategis terbaik yang harus segera dilakukan adalah memadukan atara penguatan FKK pendorong dan pelemahan FKK penghambat. Yaitu mempromosikan Barapan Kebo ke pasar pariwisata.
\end{abstract}

Kata Kunci: Barapan Kebo, CBT, Permainan rakyat, Organisasi masyarakat, Wisata budaya.

\section{Abstract}

Community-based tourism (CBT) is a tourism management concept that promises maximum benefits for the community, makes tourism inclusive for the community, and further guarantees the sustainability of tourism itself. The most likely tourist attraction managed by CBT is cultural tourism which has many attractions that are popular with tourists today. In the meantime, the Barapan kebo (buffalo race) is a folk game that is routinely held by the people on Sumbawa Island. This study aims to identify the suitability of the barapan kebo to be CBT attraction and analyze the strategic steps that need to be taken to make barapan kebo as a CBT attraction. The tool used is FFA. The results show that Barapan Kebo deserves to be a CBT attraction and its Success Key of Driving Factor is the fondness of tourists towards unique culture and its Failure Key of Restraining Factor is the fact that Barapan Kebo is not yet promoted as a tourist attracton. The best strategic step option that must be done immediately is the integration between strengthening the driving key factor and weakening the restraining key factor, namely the Barapan Kebo promotion into the tourist market.

Keywords: Buffalo race, CBT, Folk game, Community organization, Cultural tourism

(C) Direktorat Kajian Strategis 


\section{PENDAHULUAN}

Pariwisata modern saat ini telah mengalami pergeseran paradigma. Dahulu wisata alam menjadi primadona. Para wisatawan mencari pantai yang indah untuk menikmati panorama laut, panorama matahari terbit, panorama matahari tenggelam, dan berjemur di pantai, sehingga hotel-hotel berbintang dan non bintang banyak dibangun di sepanjang bibir pantai. Begitu juga restoran dan kedai-kedai kopi meramaikan suasana pantai. Saat ini mereka lebih banyak mencari sesuatu yang bisa mereka lakukan di tempat mereka berwisata. Mereka lebih banyak mencari sesuatu yang unik yang tidak mereka ditemukan di tempat mereka berasal. Mereka lebih banyak berinteraksi dengan masyarakat yang ada di tempat tujuan wisata. Dahulu kegiatan wisata merupakan kegiatan yang eksklusif, saat ini bergeser menjadi kegiatan yang inklusif.

Menurut UU Nomor 10 Tahun 2009 tentang Kepariwisataan, obyek dan daya tarik wisata adalah segala sesuatu yang memiliki keunikan, keindahan, dan nilai yang berupa keanekaragaman kekayaan alam, budaya, dan hasil buatan manusia yang menjadi sasaran atau tujuan kunjungan wisatawan.

Definisi lain menurut Yoeti (2008), daya tarik wisata adalah atraksi wisata berupa apa saja yang dapat ditawarkan kepada wisatawan agar berkunjung ke suatu destinasi wisata tertentu.

Secara garis besar ada empat kelompok daya tarik bagi wisatawan, yaitu :

1. Daya tarik wisata alam. Yang masuk dalam kelompok ini adalah pemandangan daratan, pemandangan laut, pantai, danau, air terjun, kebun raya, agrowisata, gunung berapi, termasuk juga flora dan fauna.

2. Daya tarik wisata buatan. Yang masuk dalam kelompok ini adalah bangunan dengan arsitektur yang menarik seperti Opera Buiding di Sidney, Jam Gadang di Padang, Taman Mini Indoensia Indah (TMII) di Jakarta, termasuk juga keunikan rumah adat di beberapa daerah.

3. Daya tarik wisata budaya. Yang masuk dalam kelompok ini antara lain peninggalan sejarah, cerita rakyat, kesenian tradisional, museum, upacara keagamaan, festival kesenian, dan semacamnya.

Suatu daya tarik wisata harus memenuhi syarat-syarat untuk pengembangan daerahnya, menurut Maryani (1997) syarat-syarat tersebut, meliputi:

1. What to see yaitu di tempat tersebut harus ada daya tarik atau atraksi wisata yang berbeda dengan yang dimiliki daerah lain. Dengan kata lain daerah tersebut harus memiliki daya tarik khusus dan atraksi budaya yang dapat dijadikan "entertainment" bagi wisatawan. What to see meliputi pemandangan alam, kegiatan, kesenian dan atraksi wisata,

2. What to do yaitu di tempat tersebut selain banyak yang dapat dilihat dan disaksikan, harus disediakan fasilitas rekreasi yang dapat membuat wisatawan betah tinggal lama ditempat itu,

3. What to buy yaitu tempat tujuan wisata harus tersedia fasilitas untuk berbelanja terutama barang souvenir dan kerajinan rakyat sebagai oleh-oleh untuk di bawa pulang ke tempat asal,

4. What to arrived yaitu di dalamnya termasuk aksesbilitas, bagaimana kita mengunjungi daya tarik wisata tersebut, kendaraan apa yang akan digunakan dan berapa lama tiba ketempat tujuan wisata tersebut, dan

5. What to stay yaitu bagaimana wisatawan akan tingggal untuk sementara selama dia berlibur. Diperlukan penginapanpenginapan baik hotel berbintang atau hotel non berbintang dan sebagainya.

Sebuah survey yang dilakukan oleh kementerian pariwisata Indonesia menunjukkan data bahwa para wisatawan saat ini lebih banyak memilih wisata budaya daripada wisata alam.

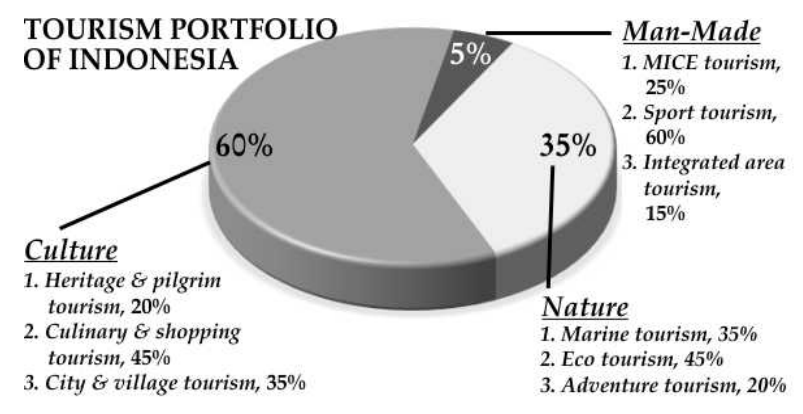

Gambar 1. Grafik Portofolio Produk Wisata. Sumber: Kementerian Pariwisata, (2018) diolah.

Menurut data Kementerian Pariwisata RI Tahun 2020, jumlah wisatawan mancanegara 
yang masuk pada tahun 2019 sebanyak 16.106 .954 orang wisatawan, naik $1,88 \%$ dari data tahun 2018 sebesar 15.810.305 (Kemenparekraf, 2020). Jika portofolio pada Grafik 1 diproyeksikan kepada data kunjungan wisatawan mancanegara 2019 maka 60\% dari mereka atau sebanyak 9.664 .172 orang memilih wisata budaya, lebih jauh lagi, $45 \%$ dari wisatawan budaya tersebut atau sebanyak 4.348.878 orang memilih wisata belanja dan kuliner, dan $35 \%$ atau sebanyak 3.382 .460 memilih wisata kota dan pedesaan.

Fenomena perubahan paradigma pariwisata ini membuat kementerian pariwisata Indonesia untuk memberikan perhatian yang sangat besar terhadap Pariwisata Berbasis Masyarakat, Community-Based Tourism CBT. Kementerian menganjurkan semua pemerintah daerah untuk mengembangkan CBT. Hai itu karena wisata budaya akan berlanjut dan berkembang jika dikelola dengan menerapkan konsep CBT.

Ardika (2018) ketika mengupas tentang periwisata berkelanjutan mengayatakan bahwa keberlanjutan pariwisata hanya akan dapat terwujud jika masyarakat bertindak menjadi pelaku dan bukan sebagai penonton. Dalam hal ini konsep CBT merupakan jawaban yang ideal bagi model pengelolaan pariwisata di Indonesia.

Di Kabupaten Sumbawa Barat terdapat permainan rakyat yang unik, yaitu Barapan Kebo. Permainan yang diadakan secara rutin oleh masyarakat. Sayangnya belum dikelola sebagai daya tarik wisata.

Berbagai pihak yang terkait, khususnya masyarakat adat telah menyuarakan aspirasi mereka untuk mengangkat Barapan Kebo sebagai daya tarik wisata andalan untuk mendampingi atraksi wisata yang sudah dimiliki oleh Kabupaten Sumbawa Barat, yaitu wisata alam bahari, serta wisata selancar ombak dan paralayang sebagai wisata olahraga dan wisata petualangan.

Menurut Iskandarsyah (2019) wisata petualangan mempunyai karakteristik yang khas. Keunikan tersebut dikarenakan kemampuan wisata petualangan untuk menggabungkan atraksi wisata alam dengan atraksi budaya lokal sehingga menjadi sebuah potensi pengembangan yang khas.

Aspirasi masyarakat tersebut terpicu oleh informasi tentang karapan sapi di Madura dan Makepung di Bali yang dapat mengundang kunjungan wisatawan, baik mancanegara maupun nusantara.

Terdapat beberapa definisi tentang CBT yang dikemukakan oleh para ahli. CBT adalah pariwisata yang concern kepada keberlanjutan lingkungan, sosial, dan budaya dalam masyarakat. (Suansri, 2003); Suatu keterpaduan pola pendekatan dan perlengkapan dalam memberdayakan ekonomi masyarakat melalui pengenalan, pengembangan, dan promosi sumberdaya yang ada pada masyarakat, baik alam maupun budaya. (Pantin dan Francis, 2005); Konsep pariwisata yang dimiliki dan dikelola oleh masyarakat dengan tujuan untuk memaksimalkan manfaat bagi masyarakat luas. (Goodwin dan Santili, 2009); Sebuah pendayagunaan sumberdaya masyarakat yang mencakup sumberdya alam, sumberdaya sosial, sumberdaya ekonomi, sumberdaya seni tradisi, kelembagaan, juga keramahtamahan masyarakat yang memegang peranan penting dalam pariwisata (Baiquni dalam Susanti, 2017).

Mengutip Goodwin and Santilli (2009), Anuar dan Sood (2017) menyebutkan beberapa manfaat yang akan didapatkan melalui konsep CBT, di antaranya sebagai berikut:

1. CBT memberi peluang yang lebih besar bagi penciptaan lapangan kerja dan peluang kewirausahaan bagi masyarakat dari beragam latar belakang, keterampilan, dan pengalaman.

2. CBT mendukung upaya meraih pendapatan, penganekaragaman ekonomi lokal, pelestarian budaya, pelestarian lingkungan hidup, dan menyediakan peluang pendidikan.

Dipandang dari manfaatnya tersebut konsep CBT pun dapat menjadi salahsatu alat dalam upaya mengurangi kemiskinan. Implementasi dari definisi CBT tersebut dikawal dengan beberapa prinsip. Hatton (2000) mengategorikan 4 prinsip:

1. Prinsip sosial, berkaitan dengan wewenang masyarakat dalam mengelola kegiatan wisata yang ada di tempat mereka.

2. Prinsip ekonomi, berkaitan dengan pembagian manfaat ekonomi yang didapatkan dari pengembangan industri pariwisata di tempat mereka.

3. Prinsip budaya, berkaitan dengan upaya menghargai budaya lokal.

4. Prinsip politik, berkaitan dengan peran pemerintah dalam mendukung CBT. 
Suansri (2003) menambahkan prinsip lingkungan, sehingga terdapat 5 prinsip sebagai berikut:

1. Prinsip ekonomi, dengan indikator munculnya dana untuk pengembangan komunitas, lapangan kerja sektor pariwisata, dan pendapatan masyarakat lokal.

2. Prinsip sosial, dengan indikator peningkatan kualitas hidup masyarakat, kebanggan komunitas, dan pemerataan peran seluruh komponen masyarakat dalam pengelolaan pariwisata.

3. Prinsip budaya, dengan indikator penghormatan terhadap budaya.

4. Prinsip lingkungan, dengan indikator pelestarian lingkungan.

5. Prinsip politik, dengan indikator peningkatan partisipasi masyarakat dan dukungan pemerintah setempat.

Lebih lanjut Suansri memaparkan beberapa langkah aplikatif dalam mewujudkan kelima prinsip CBT sebagai berikut:

1. Mengidentifikasi, mengangkat dan memromosikan kepemilikan masyarakat dalam pariwisata.

2. Melibatkan masyarakat dalam setiap fase dan aspek pengembangan pariwisata.

3. Mengangkat kebanggaan komunitas.

4. Meningkatkan taraf kualitas hidup.

5. Menjamin kelestarian lingkungan.

6. Melindungi keunikan budaya.

7. Mengembangkan pembelajaran lintas budaya.

8. Menghargai perbedaan budaya dan martabat manusia.

9. Membagikan manfaat dan keuntungan dari pariwisata kepada masyarakat secara proporsional.

10. Menyisihkan sebagian pendapatan untuk pengembangan masyarakat.

11. Memberikan perhatian besar terhadap hubungan masyarakat dengan lingkungan.

Tidak jauh berbeda dari Hatton (2000)

dan Suansri (2003), Ardika (2018) pun merincikan beberapa prinsip CBT sebagai berikut:

1. Pelibatan dan pemberdayaan masyarakat demi tercapainya transparansi dalam pengelolaan.

2. Kerjasama antar seluruh pemangku kepentingan.

3. Pengakuan dari otoritas yang terkait.

4. Peningkatan kesejahteraan dan martabat masyarakat.
5. Mekanisme pembagian hasil yang proporsional.

6. Peningkatan hubungan ekonomi tingkat lokal dan regional.

7. Peluhuran budaya dan tradisi lokal.

8. Kontribusi bagi pelestarian sumberdaya alam.

9. Peningkatan kualitas pengalaman wisatawan.

10. Tujuan ke arah kemandirian keuangan.

11. Pembukaan lapangan kerja sehingga berdampak pada berkurangnya urbanisasi.

Masyarakat tidak lagi menjadi objek, mereka adalah subjek dan aktor pembangunan dan pengembangan pariwisata. Dalam CBT, Pariwisata adalah dari, oleh, dan untuk masyarakat.

Edy Putra Irawady dalam Kompas (2008), menyatakan bahwa Konsep CBT merupakan strategi yang bagus untuk memberdayakan ekonomi rakyat melalui pariwisata. Mereka diikutsertakan dalam perencanaan, penerapan, dan pengawasan. Merekalah yang akan mendapatkan manfaat utama dari kegiatan pariwisata di tempat mereka. Atraksi budaya yang paling sesuai untuk dikembangkan melalui CBT adalah wisata budaya, wisata petualangan, dan wisata ekologi, karena CBT sangat sesuai bagi upaya pelestarian sumberdaya lokal berupa sumberdaya alam dan sumberdaya budaya.

Kajian ini ingin menganalisis apakah Barapan Kebo bisa dikembangkan sebagai daya tarik wisata berbasis masyarakat (CBT) sehingga nantinya tidak saja sebagai hiburan masyarakat, tetapi juga dapat memberi manfaat ekonomi lainnya bagi masyarakat.

Penelitian ini bertujuan untuk menjawab beberapa pertanyaan sebagai berikut:

1. Apakah barapan kebo layak sebagai daya tarik wisata berbasis masyarakat (CBT)?

2. Bagaimana posisi Barapan Kebo menurut Analisis Medan Kekuatan (AMK)?

3. Langkah strategis apa yang disarankan agar Barapan Kebo menjadi daya tarik wisata berbasis masyarakat (CBT)?

\section{METODE}

Penelitian ini adalah penelitian kualitatif yang datanya dikumpulkan dari dokumentasi dan curah pendapat narasumber dalam FGD.

Para narasumber adalah mereka yang dinilai sangat memahami karakteristik Barapan 
Kebo dan memahami hubungannya dengan faktor-faktor yang menjadi variabel dalam penelitian ini yang terdiri dari:

1. Pengurus Lembaga Adat.

2. Pengurus Masyarakat Barapan Kebo.

3. Wakil dari pencinta Barapan Kebo.

4. Wakil dari instansi pemerintah bidang kepariwisataan.

5. Wakil dari pelaku usaha kepariwisataan. Analisis terhadap Barapan Kebo dilakukan dua tahap:

1. Asesmen prinsip-prinsip CBT untuk mengukur apakah Barapan Kebo memiliki unsur-unsur yang sesuai dengan prinsipprinsip CBT.

2. Analisis Medan Kekuatan (AMK)

AMK merupakan alat analisis strategis yang fungsi utamanya adalah untuk membandingkan antara kekuatan pendorong dan kekuatan penghambat bagi suatu perubahan dalam hal ini menjadikan barapan kebo sebagai daya tarik berbasis masyarakat (CBT). Dalam Analisis Medan Kekuatan data-datanya dikuantisir sehingga analisisnya menggunakan analisis kuantitatif (Mindtools, 2014).

Proses Analisis Medan Kekuatan (AMK) didesain dalam beberapa tahapan sebagai berikut:

a. Dalam FGD para narasumber diminta curah pendapat tentang hal-hal yang terkait dengan tujuan menjadikan barapan kebo sebagai daya tarik wisata berbasis masyarakat (CBT), baik halhal yang menguntungkan atau merugikan, yang positif atau yang negatif, yang mendorong atau menghambat.

b. Berikutnya para narasumber memilih beberapa faktor yang dinilai memiliki daya dorong atau daya hambat yang paling besar bagi tujuan perubahan.

c. Untuk setiap faktor diukur bobotnya, daya dorong/hambatnya, dan nilai keterkaitan antar faktor.

d. Narasumber melakukan pembobotan faktor melalui perbandingan urgensi antar faktor. Frekuensi keterpilihan suatu faktor sebagai faktor yang lebih urgen dari faktor lainnya akan mempengaruhi bobotnya. Pada bagian ini setiap bobot akan memiliki nilai Bobot Faktor (BF).

e. Pengukuran daya dorong faktor-faktor pendorong dan daya hambat faktorfaktor penghambat dilakukan oleh para narasumber secara intuitif berdasarkan pengamatan dan pengalaman yang kemudian disepakati di dalam diskusi. Penilaian dibuat dalam 5 skala: sangat kuat, kuat, cukup, lemah, dan sangat lemah yang dikuantisir menjadi angka 5 untuk sangat kuat dan 1 untuk sangat lemah. Setiap faktor akan memiliki Nilai Daya dorong/hambat (ND).

f. Hal yang sama dilakukan oleh para narasumber dalam memberikan nilai keterkaitan antar faktor. Pada bagian ini setiap faktor akan memiliki Nilai Rerata Kaitan (NRK).

g. Data nilai yang didapatkan diproses untuk mencari Total Nilai Bobot (TNB) setiap kelompok: pendorong dan penghambat. TNB adalah hasil penjumlahan NBD (Nilai Bobot Daya dorong/hambat) dengan NBK (Nilai Bobot Kaitan).

h. NBD adalah hasil perkalian antara BF dengan ND. NBK adalah hasil perkalian antara BF dengan NRK).

i. TNB setiap faktor pada setiap kelompok dijumlahkan sehingga diketahui TNB kelompok faktor mana yang lebih besar.

j. Pada setiap kelompok faktor dicari Faktor Kunci Keberhasilan (FKK), yaitu faktor dengan TNB terbesar.

k. Berdasarkan TNB kelompok faktor dan FKKnya disusun langkah strategi yang sesuai. Jika faktor pendorong lebih besar maka langkah yang direkomendasikan adalah memperkuat FKK pendorong. Jika faktor penghambat yang lebih besar maka langkah yang direkomendasikan adalah memperlemah FKK penghambat. Jika antara FKK pendorong dan FKK penghambat memiliki keterkaitan yang cukup besar maka langkah strategis yang direkomendasikan adalah perpaduan antara penguatan FKK pendorong dengan pelemahan FKK peghambat.

\section{HASIL DAN PEMBAHASAN}

Hasil dari penelitian ini dapat diuraikan sebagai berikut: 


\section{Barapan kebo}

Barapan Kebo adalah permainan rakyat masyarakat Samawa di Pulau Sumbawa. Permainan ketangkasan sepasang kerbau yang dikendalikan oleh seorang joki yang diadakan menjelang musim tanam di pesawahan. Tujuan permainan ini selain untuk hiburan masyarakat juga sebagai upaya menggemburkan tanah, maka Barapan Kebo diadakan di sawah berlumpur.

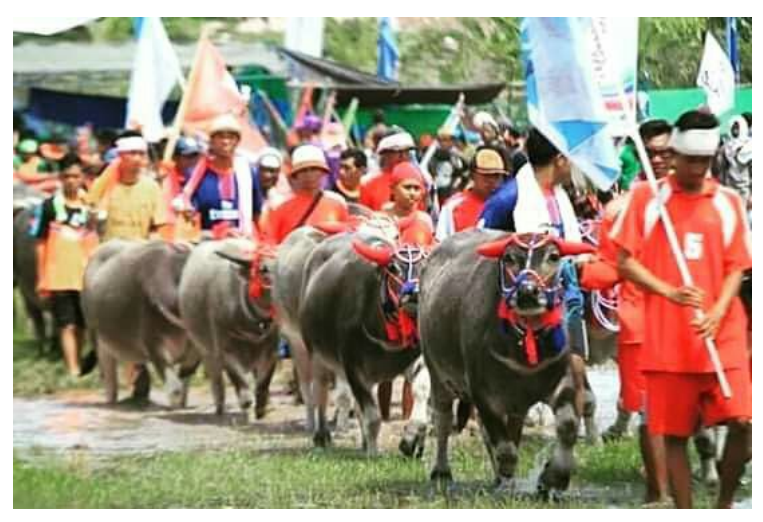

Gambar 2. Foto barisan kerbau yang akan ikut barapan. Sumber:_Nukman (2019)

Kerbau yang akan ikut barapan dihiasi dengan berbagai asesoris. Joki yang akan mengendalikan kerbau juga menggunakan asesoris pakaian adat, minimal ikat kepala tradisional yang disebut Sapuk'

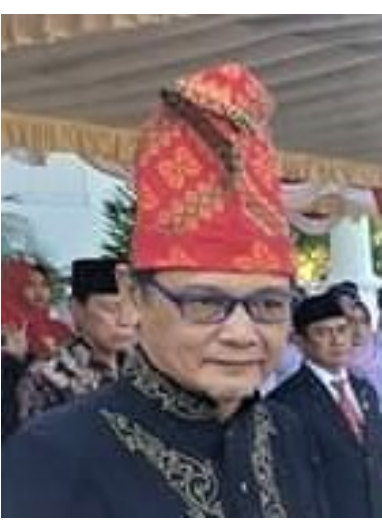

Gambar 3.

Foto Sapu', ikat kepala tradisional Samawa. Sumber: Koleksi pribadi.

Barapan kebo diselenggarakan di arena sepanjang minimal 120 meter dan lebar minimal minimal 30 meter. Jarak antara garis mula dengan garis akhir sepanjang 99 meter. Di bagian tengah garis akhir dipancangkan sebuah tiang yang menjadi sasaran yang harus dikenai. Tiang sasaran disebut dengan Saka.
Peserta barapan adalah pasangan kerbau yang dikendalikan oleh seorang joki yang berdiri di antara dua ekor kerbau yang satu sama lain disatukan dengan Noga, kayu yang diletakkan di atas pundak kedua kerbau, dan terhubung dengan Kareng, tempat berdiri joki. Menjadi joki dalam barapan disebut entek kareng, ungkapan bahasa Samawa yang artinya berdiri di atas kareng dalam mengendalikan sepasang kerbau barapan

Dalam satu even barapan kebo biasanya akan diikuti oleh puluhan bahkan ratusan pasangan kerbau yang datang dari berbagai pelosok. Masing-masing pasangan kerbau memiliki nama yang didaftarkan dan akan mendapat nomor giliran berpacu.

Tidak seperti lomba kecepatan binatang lainnya, misalnya pacuan kuda, dimana dua atau lebih binatang pacuan mulai berlari dari garis start pada waktu yang sama dan pemenangnya adalah binatang mana yang mencapai garis finish paling awal, pada barapan kebo, pemilihan pemenang dipilih dari dua hal secara berurutan. Pertama, pasangan kerbau yang berhasil mengenai saka, yaitu sebuah tiang yang dipancang di bagian tengah garis akhir; kedua, pasangan kerbau mana yang tercepat dalam mengenai saka. Dengan demikian, barapan kebo bukan sekedar adu kecepatan pasangan kerbau, tetapi yang lebih utama adalah pengendalian seorang joki atas pasangan kerbaunya.

Pasangan kerbau yang akan berpacu dipersiapkan oleh joki, pemilik kerbau, dan beberapa orang pembantunya di area yang berada di belakang garis mula. Saat giliran tiba, pasangan kerbau dengan seorang joki yang berdiri di antara kedua kerbau tersebut bersiapsiap di garis mula menunggu petugas garis mula mengibarkan bendera sebagai tanda pasangan kerbau mulai berpacu. Saat itu petugas waktu menekan stopwatch untuk memulai perhitungan waktu. 


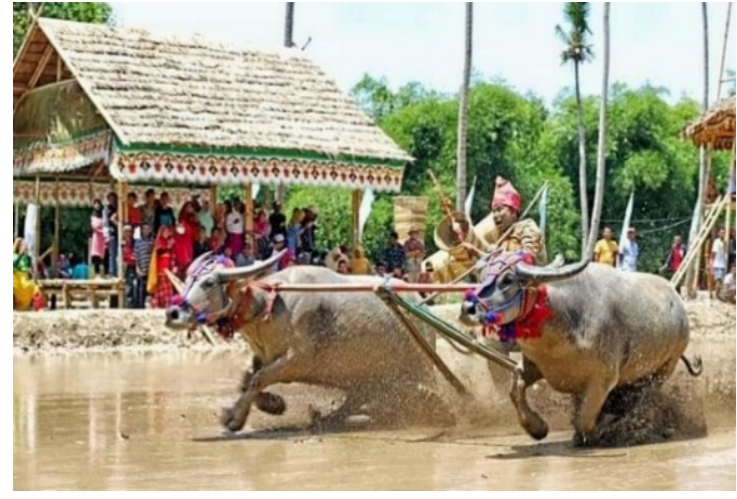

Gambar 4. Foto seorang joki sedang memacu kerbaunya. Sumber: Paryati (2019)

Joki akan segera mengendalikan pasangan kerbau secepat mungkin menuju saka dan mengenainya. Jika pasangan kerbau mencapai garis akhir, petugas garis akhir mengibarkan bendera. Di saat itu pula petugas waktu menekan stopwatch untuk mengakhiri perhitungan waktu.

Ada dua warna bendera yang dipegangnya: satu bendera menandakan bahwa pasangan kerbau berhasil mengenai saka, bendera lainnya menandakan bahwa pasangan kerbau gagal mengenai saka.

Catatan nama-nama pasangan kerbau yang berhasil mengenai saka akan diperingkatkan berdasarkan kecepatannya mengnganenai saka. Yang tercepat adalah pemenangnya. Biasanya akan dipilih 3 sampai 10 pemenang berdasarkan ketersediaan hadiah yang disiapkan oleh penyelenggara.

Even barapan kebo seringkali diselenggarakan oleh masyarakat, tepatnya Masyarakat Barapan Kebo, organisasi masyarakat pecinta barapan kebo yang anggotanya terdiri dari para pemilik kerbau, para pemelihara kerbau, para joki, para sandro, sebutan bagi mereka yang dianggap memiliki kekuatan spiritual untuk membuat suatu pasangan kerbau menang di barapan, serta pecinta barapan kebo.

Even besar barapan kebo diadakan sekali setahun, tepatnya menjelang hari ulang tahun Kabupaten Sumbawa Barat. Selain itu diselenggarakan pula even-even lain secara rutin sebulan sekali, bahkan untuk skala yang lebih kecil diadakan setiap hari minggu.

Untuk setiap pasangan kerbau yang menjadi peserta even wajib didaftarkan namanya dengan biaya pendaftaran sekitar Rp 100.000,- (7,5 US\$). Dalam suatu even sedang bisa diikuti oleh 200 pasang kerbau, bahkan lebih, sehingga dana yang terkumpul dari pendaftaran bisa mencapai Rp 25 juta (1.800 US\$) yang sebagian digunakan untuk penyediaan hadiah bagi pemenang, sebagian untuk honor panitia, dan sebagian disalurkan untuk dana organisasi. Seringkali ada bantuan dari pemerintah atau dana sponsor dari beberapa perusahaan yang digunakan untuk hal yang sama. Jumlah peserta even besar bisa mencapai dua atau tiga kali lipat daripada jumlah peserta even sedang.

Biaya penyelenggaraan even relatif tidak mahal bagi penyelenggara, namun cukup mahal bagi pemilik kerbau. Biaya itu mencakup penyiapan kerbau dengan berbagai suplemen, asesoris penghias kerbau, sewa kendaraan untuk mengangkut kerbau, para pemelihara kerbau, joki, sandro, dan para suporter, biaya konsumsi, biaya registrasi, dan biaya sewa joki.

Harga seekor kerbau biasa yang belum terlatih sekitar Rp 14 juta (1.000 US\$). Bila sudah sangat terlatih harganya bisa mencapai Rp 32 juta (3.000 US\$).

Kemenangan pasangan kerbau dalam suatu barapan kebo akan mengangkat prestise pasangan kerbau tersebut dan menaikkan harga jual, juga menaikkan prestise joki sehingga akan disewa oleh pemilik kerbau pada even barapan kerbau berikutnya.

Menjadi joki tidak sulit. Yang dibutuhkan hanyalah kemampuan untuk memacu kerbau agar berlari cepat, mengendalikan kerbau agar arah larinya menuju saka, juga menjaga keseimbangan sehingga tidak terlepas pegangan dan terlempar karena licinnya lumpur. Tetapi tidak mudah mengarahkan sepasang kerbau untuk mengenai sasaran: Saka. Ini permainan yang menantang, ini petualangan.

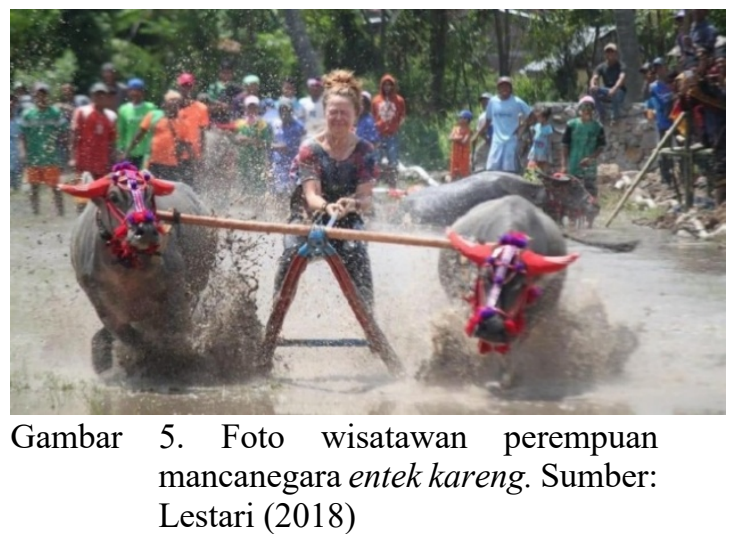


Biasanya, sebelum mengikuti even barapan kebo, para joki sudah berlatih terlebih dahulu dengan sepasang kerbau yang akan ikut barapan di tempat masingmasing, yaitu sawah mereka sendiri yang juga sudah diairi sehingga menjadi tanah berlumpur.

Penyelenggaraan even barapan kebo menjadi sumber pendapatan tambahan dadakan bagi para penjual keliling makanan ringan dan minuman, juga bagi masyarakat sekitar tempat penyelenggaraan even untuk membuka warung makanan dan minuman. Ini manfaat ekonominya. Dari aspek sosial, terjadinya peristiwa tolong-menolong dari penduduk di sekitar tempat penyelenggaraan even kepada rombongan pemilik kerbau yang datang dari jauh, berupa penyediaan rumah penduduk menjadi tempat istirahat, tempat mandi dan membersihkan diri.

\section{Analisis Prinsip CBT}

Untuk mengukur apakah Barapan Kebo masuk kategori CBT perlu dibedah untuk mengetahui terpenuhinya prinsipprinsip CBT.

Tolok ukurnya adalah 5 prinsip Suansri (2003), Hasilnya pada Tabel 1.

Tabel 1. Kesesuaian Barapan Kebo dalam Prinsip CBT

\begin{tabular}{|c|c|c|}
\hline PRINSIP CBT & TEMUAN DI BARAPAN KEBO & SESUAI? \\
\hline \multicolumn{3}{|l|}{ Prinsip Ekonomi } \\
\hline $\begin{array}{l}\text { 1. Munculnya dana untuk } \\
\text { pengembangan komunitas. }\end{array}$ & $\begin{array}{l}\text { Dalam even, terdapat dana yang berasal dari registrasi peserta, bantuan } \\
\text { pemerintah, dan sponsor dari perusahaan. Dana yang diperoleh itu }\end{array}$ & Ya \\
\hline 2. Munculnya lapangan kerja & sebagian digunakan untuk penyediaan hadiah pemenang, sebagian & \\
\hline sektor pariwisata. & untuk honor panitia penyelenggara, sebagian disalurkan untuk dana & \\
\hline 3. Peningkatan pendapatan & organisasi. & \\
\hline masyarakat lokal & Bila sudah berkembang menjadi daya tarik wisata dan muncul & \\
\hline & kebutuhan terhadap lembaga kursus/latihan joki bagi para wisatawan, & \\
\hline & mbaga penyedia kursus. Inipun merupakan & \\
\hline & lapangan kerja baru di sektor pariwisata & \\
\hline & Even barapan kebo terbukti memberi tambahan pendapatan bagi & \\
\hline & $\begin{array}{l}\text { masyarakat sekitar dan bagi komunitas, seperti penyediaan makanan, } \\
\text { minuman, sapuk, dan sebagainya. }\end{array}$ & \\
\hline
\end{tabular}

Prinsip Sosial

1. Peningkatan kualitas hidup masyarakat

2. Kebanggaan komunitas

3. Pemerataan peran seluruh komponen masyarakat dalam pengelolaan pariwisata

4. Mekanisme penguatan organisasi komunitas

Barapan kebo bagi pemilik kerbau adalah sebuah prestige, tetapi bagi $\mathrm{Ya}$ pemelihara kerbau, joki, dan pihak lain yang terlibat merupakan sumber penghidupan.

Sebagai permainan rakyat warisan budaya, masyarakat sangat gemar memainkan dan menjadi kebanggaan bersama masyarakat Sumbawa. Organisasi masyarakat Barapan Kebo melibatkan semua unsur masyarakat yang mencintai barapan kebo. Merekalah yang memiliki inisiatif untuk menyelenggarakan even dan melestarikan keberadaaannya. Pemerintah dan dunia usaha hanya mendukung.

\section{Prinsip Budaya}

1. Penghormatan terhadap budaya

2. Pertukaran budaya

3. Adanya budaya pembangunan yang melekat erat dalam budaya lokal

Prinsip Lingkungan

1. Pengembangan carryng capacity Barapan kebo dilaksanakan di area pesawahan yang sudah dipanen dan Ya area

2. Sistem pembuangan sampah yang ramah lingkungan akan digarap lagi untuk masa tanam berikutnya.

Sebuah permainan rakyat yang merupakan warisan budaya. Tradisi $\mathrm{Ya}$ alikan pasangan kerbau dan aturan permainan merupakan proses pertukaran budaya yang halus. Masyarakat barapan Kebo terus mengembang-biakkan kerbau yang unggul.

3. Keperdulian tentang pentingnya konservasi

\section{Prinsip Politik}

1. Partisipasi penduduk lokal

2. Meningkatkan kekuasaan komunitas yang lebih luas

3. Mekanisme yang menjamin hak- Masyarakat memegang penuh kendali terhadap barapan kebo. 
Tabel 1 di atas menggambarkan bahwa barapan kebo sebagai permainan rakyat masyarakat Sumbawa memenuhi kriteria prinsip-prinsip CBT sehingga layak untuk dijadikan daya tarik wisata budaya CBT.

3. Analisis Medan Kekuatan

Dari FGD ditemukan faktor-faktor pendorong dan penghambat bagi barapan kebo untuk menjadi daya tarik berbasis masyarakat (CBT) berikut:

Faktor Pendorong:

1) Barapan Kebo merupakan kegiatan olahraga petualangan.

2) Barapan Kebo merupakan permainan rakyat dan budaya yang unik.

3) Biaya murah bagi wisatawan yang ingin mencoba menjadi joki barapan.

4) Terdapat organisasi masyarakat khusus Barapan Kebo.

5) Barapan Kebo bisa dimainkan di semua musim dengan syarat tempat permainannya berupa tanah berumpur.

6) Wisatawan menyukai atraksi wisata petualangan.

7) Wisatawan menyukai atraksi wisata budaya yang unik.

8) Paralayang dan selancar ombak sudah 
Tabel 3. Bobot Faktor Penghambat

\begin{tabular}{llcccccccccccc}
\hline FAKTOR PENGHAMBAT & H1 & H2 & H3 & H4 & H5 & H6 & H7 & H8 & H9 & H10 & NU & BOBOT \\
\hline H1 & Belum dikemas & $*$ & 1 & 1 & 1 & 1 & 1 & 1 & 1 & 1 & 10 & 8 & 17,8 \\
H2 & Belum dipasarkan & 1 & $*$ & 2 & 2 & 2 & 2 & 2 & 2 & 2 & 2 & 8 & 17,8 \\
H3 & Ada praktek menyakiti hewan & 1 & 2 & $*$ & 4 & 3 & 6 & 7 & 8 & 3 & 10 & 2 & 4,4 \\
H4 & Tingkat keselamatan sedang & 1 & 2 & 4 & $*$ & 4 & 6 & 4 & 4 & 4 & 4 & 6 & 13,3 \\
H5 & Populasi kerbau kurang & 1 & 2 & 3 & 4 & $*$ & 6 & 7 & 8 & 5 & 10 & 1 & 2,2 \\
H6 & Pasar belum banyak kenal & 1 & 2 & 6 & 6 & 6 & $*$ & 6 & 6 & 6 & 6 & 7 & 15,6 \\
H7 & Orang takut menjadi joki & 1 & 2 & 7 & 4 & 7 & 6 & $*$ & 7 & 7 & 7 & 5 & 11,1 \\
H8 & Kab. Sumbawa sudah mulai promosi & 1 & 2 & 8 & 4 & 8 & 6 & 7 & $*$ & 8 & 10 & 3 & 6,7 \\
H9 & Fasilitas pariwisata kurang & 1 & 2 & 3 & 4 & 5 & 6 & 7 & 8 & $*$ & 9 & 1 & 2,2 \\
H10 & Masyarakat belum mendapat manfaat & 10 & 2 & 10 & 4 & 10 & 6 & 7 & 10 & 9 & $*$ & 4 & 8,9 \\
\hline & TOTAL & & & & & & & & & $\mathbf{4 5}$ & $\mathbf{1 0 0}$ \\
\hline
\end{tabular}

Nilai Urgensi dan Bobot Faktor seluruh faktor, baik yang mendorong maupun yang menghambat, dimasukkan dalam tabel berikutnya pada kolom NU dan BF untuk mencari Total Nilai Bobot (TNB) melalui perhitungan beberapa nilai (Sianipar dan Entang, 2003) sebagai berikut:

1. ND (Nilai Dukungan): Penilaian dorongan atau hambatan faktor dengan skala 1 (terkecil) sampai 5 (terbesar).

2. NBD (Nilai Bobot Dukungan):

Perkalian BF dan ND dibagi 100.

3. NK (Nilai Keterkaitan): keterkaitan antar faktor yang dinilai dengan skala 1 (keterkaitan terlemah) sampai dengan 5 (keterkaitan terkuat).

4. NRK (Nilai Rata Keterkaitan): Total NK dibagi banyaknya faktor

5. NBK (Nilai Bobot Keterkaitan): Perkalian BF dan NRK dibagi 100

6. TNB (Total Nilai Bobot): NBD ditambah NBK.

Berdasarkan rumus-rumus pencarian nilai-nilai tersebut di atas dilakukan perhitungan TNB dari keseluruhan faktor seperti yang tertera pada Tabel 4.

Tabel 4. Perhitungan Total Nilai Bobot AMK

\begin{tabular}{ccccccccccccccccccccccccccccccc}
\hline \multirow{2}{*}{$\begin{array}{c}\text { FAK } \\
\text { TOR }\end{array}$} & NU & BF & ND & N & BD & D1 & D2 & D3 & D4 & D5 & D6 & D7 & D8 & D9 & D10 & H1 & H2 & H3 & H4 & H5 & H6 & H7 & H8 & H9 & H10 & RK & BK & NB \\
\hline D1 & 7 & 15,6 & 4 & 0,62 & $*$ & 5 & 1 & 3 & 4 & 4 & 5 & 3 & 4 & 3 & 5 & 4 & 4 & 2 & 1 & 4 & 3 & 3 & 2 & 1 & 3,2 & 0,5 & 1,1 \\
D2 & 7 & 15,6 & 4 & 0,62 & 5 & $*$ & 2 & 5 & 5 & 4 & 5 & 4 & 4 & 4 & 5 & 5 & 3 & 3 & 4 & 4 & 4 & 3 & 2 & 2 & 3,8 & 0,6 & 1,2 \\
D3 & 3 & 6,7 & 2 & 0,13 & 1 & 2 & $*$ & 1 & 1 & 2 & 2 & 1 & 1 & 1 & 3 & 3 & 1 & 1 & 1 & 1 & 4 & 1 & 1 & 1 & 1,5 & 0,1 & 0,2 \\
D4 & 4 & 8,9 & 3 & 0,27 & 3 & 5 & 1 & $*$ & 1 & 3 & 4 & 5 & 3 & 3 & 2 & 3 & 1 & 2 & 5 & 3 & 4 & 3 & 2 & 4 & 3,0 & 0,3 & 0,5 \\
D5 & 2 & 4,4 & 3 & 0,13 & 4 & 5 & 1 & 1 & $*$ & 2 & 3 & 1 & 1 & 2 & 3 & 2 & 1 & 1 & 1 & 1 & 1 & 3 & 1 & 1 & 1,8 & 0,1 & 0,2 \\
D6 & 8 & 17,8 & 5 & 0,89 & 4 & 4 & 2 & 3 & 2 & $*$ & 5 & 3 & 4 & 1 & 5 & 5 & 4 & 4 & 4 & 4 & 4 & 3 & 2 & 2 & 3,4 & 0,6 & 1,5 \\
D7 & 8 & 17,8 & 5 & 0,89 & 5 & 5 & 2 & 4 & 3 & 5 & $*$ & 2 & 2 & 1 & 5 & 5 & 4 & 4 & 3 & 6 & 4 & 3 & 2 & 2 & 3,5 & 0,6 & 1,5 \\
D8 & 2 & 4,4 & 4 & 0,18 & 3 & 4 & 1 & 5 & 1 & 3 & 2 & $*$ & 1 & 1 & 1 & 4 & 1 & 1 & 4 & 1 & 2 & 2 & 1 & 1 & 2,1 & 0,1 & 0,3 \\
D9 & 6 & 13,3 & 3 & 0,40 & 4 & 4 & 1 & 3 & 1 & 4 & 2 & 1 & $*$ & 1 & 4 & 3 & 3 & 3 & 3 & 3 & 5 & 3 & 2 & 1 & 2,7 & 0,4 & 0,8 \\
D10 & 1 & 2,2 & 2 & 0,04 & 3 & 4 & 1 & 3 & 2 & 1 & 1 & 1 & 1 & $*$ & 1 & 2 & 1 & 3 & 3 & 1 & 1 & 2 & 1 & 1 & 1,7 & 0,0 & 0,1 \\
H1 & 6 & 13,3 & 4 & 0,53 & 5 & 5 & 3 & 2 & 3 & 5 & 5 & 1 & 4 & 1 & $*$ & 5 & 5 & 2 & 4 & 5 & 4 & 4 & 3 & 3 & 3,6 & 0,5 & 1,0 \\
H2 & 9 & 20,0 & 5 & 1,00 & 4 & 5 & 3 & 3 & 2 & 5 & 5 & 4 & 3 & 2 & 5 & $*$ & 2 & 3 & 4 & 4 & 3 & 4 & 3 & 1 & 3,4 & 0,7 & 1,7 \\
H3 & 5 & 11,1 & 3 & 0,33 & 4 & 3 & 1 & 1 & 1 & 4 & 4 & 1 & 3 & 1 & 5 & 2 & $*$ & 3 & 1 & 3 & 1 & 3 & 1 & 1 & 2,3 & 0,3 & 0,6
\end{tabular}




\begin{tabular}{cccccccccccccccccccccccccccc} 
H4 & 1 & 2,2 & 3 & 0,07 & 2 & 3 & 1 & 2 & 1 & 4 & 4 & 1 & 3 & 3 & 2 & 3 & 3 & $*$ & 3 & 3 & 2 & 3 & 5 & 2 & 2,6 & 0,1 & 0,1 \\
H5 & 1 & 2,2 & 1 & 0,02 & 1 & 4 & 1 & 5 & 1 & 4 & 3 & 4 & 3 & 3 & 4 & 4 & 1 & 3 & $*$ & 2 & 3 & 3 & 2 & 5 & 2,9 & 0,1 & 0,1 \\
H6 & 7 & 15,6 & 5 & 0,78 & 4 & 4 & 1 & 3 & 1 & 4 & 6 & 1 & 3 & 1 & 5 & 4 & 3 & 3 & 2 & $*$ & 4 & 4 & 3 & 2 & 3,1 & 0,5 & 1,3 \\
H7 & 5 & 11,1 & 3 & 0,33 & 3 & 4 & 4 & 4 & 1 & 4 & 4 & 2 & 5 & 1 & 4 & 3 & 1 & 2 & 3 & 4 & $*$ & 3 & 4 & 3 & 3,1 & 0,3 & 0,7 \\
H8 & 3 & 6,7 & 3 & 0,20 & 3 & 3 & 1 & 3 & 3 & 3 & 3 & 2 & 3 & 2 & 4 & 4 & 3 & 3 & 3 & 4 & 3 & $*$ & 3 & 1 & 2,8 & 0,2 & 0,4 \\
H9 & 1 & 2,2 & 2 & 0,04 & 2 & 2 & 1 & 2 & 1 & 2 & 2 & 1 & 2 & 1 & 3 & 3 & 1 & 5 & 2 & 3 & 4 & 3 & $*$ & 1 & 2,2 & 0,0 & 0,1 \\
$\mathrm{H} 10$ & 4 & 8,9 & 2 & 0,18 & 1 & 2 & 1 & 4 & 1 & 2 & 2 & 1 & 1 & 1 & 3 & 1 & 1 & 2 & 5 & 2 & 3 & 1 & 1 & $*$ & 1,8 & 0,2 & 0,3 \\
\hline
\end{tabular}

Data yang tertera pada Tabel 4 di atas menggambarkan bahwa secara total Faktor Pendorong (dengan Jumlah TNB 7,4) lebih besar daripada Faktor Penghambat (dengan Jumlah TNB 6,3). Ilustrasi dari gambaran tersebut tampak pada gambar berikut:

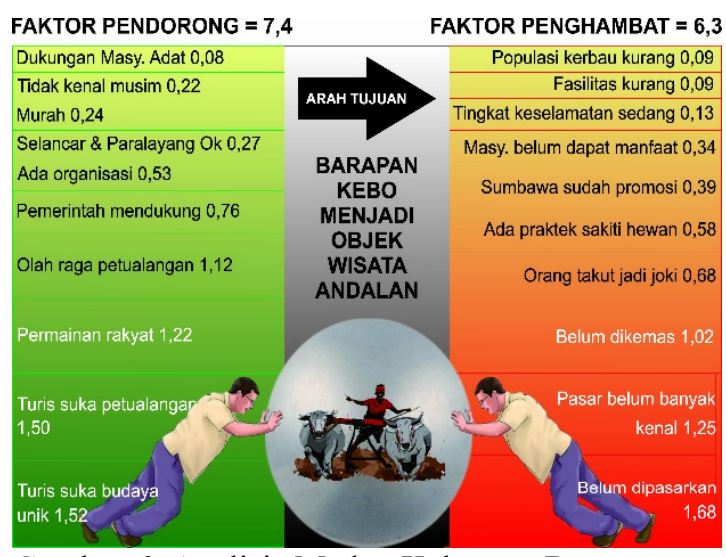

Gambar 6. Analisis Medan Kekuatan Barapan Kebo. Sumber: Data diolah.

Hal ini memberi isyarat bahwa rencana perubahan untuk menjadikan Barapan Kebo sebagai daya tarik wisata andalan dapat dilanjutkan dengan memperhatikan Faktor Kunci Keberhasilan (FKK), yakni faktor dengan TNB terbesar, baik pada kelompok Pendorong maupun pada kelompok Penghambat.

Jika diambil 5 faktor dengan nilai TNB terbesar dari masing-masing kelompok maka didapatkan data FKK sebagai berikut:

\section{FAKTOR PENDORONG}

1. Wisatawan suka budaya unik, TNB 1,52

2. Wisatawan suka petualangan, TNB 1,50

3. Barapan Kebo sebagai permainan rakyat, TNB 1,25

4. Barapan Kebo sebagai olah raga petulangan, TNB 1,15

5. Adanya dukungan Pemerintah, TNB 0,76

FAKTOR PENGHAMBAT

1. Belum dipasarkan, TNB 1,53

2. Pasar belum banyak mengenal Barapan Kebo, TNB 1,25

3. Belum dikemas sebagai daya tarik wisata, TNB 1,04

4. Orang takut menjadi joki barapan, TNB 0,68

5. Adanya praktek menyakiti hewan, TNB 0,60

Terdapat tiga opsi dalam mengambil langkah strategis perubahan: Memperkuat FKK Pendorong, atau memperlemah FKK Penghambat, atau gabungan keduanya (Fisher et al, 2007).

Jika memperhatikan FKK pada kedua kelompok faktor tersebut di atas bisa dilihat adanya empat masalah yang perlu diberi perhatian serius, yaitu:

1. Masalah pengemasan barapan kebo untuk dipasarkan menjadi daya tarik wisata sehingga bertemu dengan kesukaan wisatawan terhadap wisata petualangan dan wisata budaya (permainan rakyat).

2. Masalah keterampilan menjadi joki barapan kebo sebagai permainan petualangan yang memiliki resiko keselamatan.

3. Masalah kebiasaan joki yang menggunakan cara yang menyakiti hewan, sesuatu yang tidak disukai oleh sebagian kalangan wisatawan.

4. Masalah dukungan pemerintah dalam mengatasi tiga masalah di atas.

Opsi langkah strategis terbaik adalah gabungan antara penguatan Faktor Pendorong dan pelemahan Faktor Penghambat sebagai berikut:

1. Mengemas barapan kebo agar layak untuk dipasarkan sebagai daya tarik 
wisata andalan mendampingi selancar dan paralayang yang sudah berkembang.

2. Melakukan promosi secara intensif melalui semua saluran pemasaran yang mungkin digunakan, termasuk membonceng promosi petualangan selancar dan paralayang.

3. Memberdayakan organisasi/masyarakat Barapan Kebo untuk:
a. Membangun mindset Barapan Kebo sebagai permainan tradisional yang bisa dijual sebagai daya tarik wisata juga.
b. Meniadakan praktek menyakiti hewan dalam barapan.
c. Menyediakan jasa kursus atau latihan menjadi joki barapan kebo bagi wisatawan.

4. Mengarahkan dukungan Pemerintah Daerah terhadap langkah-langkah strategis tersebut di atas.

\section{SIMPULAN}

Hasil Analisis Medan Kekuatan menunjukkan bahwa kekuatan pendorong untuk menjadikan Barapan Kebo sebagai daya tarik berbasis masyarkat (CBT) di Kabupaten Sumbawa Barat lebih besar dari kekuatan penghambat dengan saran strategi memadukan langkah penguatan Faktor Kunci pendorong dan pelemahan Faktor Kunci penghambat, yakni terkait pemasaran, latihan/ kursus joki barapan, dan pemberdayaan masyarakat Barapan Kebo sebagai penerapan konsep CBT

Berdasarkan simpulan kajian tersebut di atas maka direkomendasikan beberapa langkah strategis sebagai berikut:

1. Intensifikasi aksi promosi dan pemasaran melalui:

a. Pengadaan even besar tahunan barapan kebo secara rutin dengan penetapan waktu dan tempat yang diupayakan tidak berubah.

b. Pengadaan even barapan kebo rutin dengan skala lebih kecil yang diadakan lebih sering, minimal sebulan sekali.

c. Penyiaran even barapan kebo melalui seluruh sarana yang mungkin digunakan, internet, baliho, flyer, dan sebagainya secara intensif dan massif.

d. Berkerjasama dengan dunia usaha kepariwisataan dalam pengenalan dan promosi barapan kebo, seperti agen perjalanan wisata, perusahaan transportasi, perhotelan, rumah makan, dan sebagainya.

2. Memberdayakan masyarakat barapan kebo sebagai aktor pelaksana dalam konsep CBT (community-based tourism) dengan beberapa aksi awal:

a. Menanam mindset bahwa barapan kebo layak dijadikan sebagai daya tarik wisata.

b. Mengemas penyelenggaraan even barapan kebo lebih layak pasar.

d. Merubah mindset cara mengendalikan kerbau tanpa menggunakan cara yang menyakiti hewan.

e. Mengajak berpartisipasi sebagai provider pengadaan kursus/latihan dan praktek menjadi joki barapan bagi para wisatawan dan masyarakat.

3. Mengarahkan dukungan pemerintah kepada

a. Pemberdayaan masyarakat barapan kebo.

b. Peningkatan kapasitas managerial dalam mengemas barapan kebo sebagai daya tarik wisata andal.

c. Fasilitasi izin pendirian kursus/latihan termasuk praktek menjadi joki barapan kebo dengan jaminan keselamatan.

\section{DAFTAR PUSTAKA}

\section{$\underline{\text { Buku }}$}

Ardika, IG, (2018), Kepariwisataan berkelanjutan, rintis jalan lewat komunitas, Jakarta: Kompas Media Nusantara.

Fisher, S., Abdi, D. I., Ludin, J., Smith, R., Williams, S., \& Williams, S., (2007), Working with conflict: skills and strategies for action, London: Zed Books.

Hatton, Michael J. (2000), Community-based tourism in the Asia-Pacific, Toronto: School of Media Studies at Humber College.

Iskandarsyah, M. (2019), Buku kajian wisata petualangan, Ponorogo: Uwais Inspirasi Indonesia

Kementerian Pariwisata, (2018), Rencana strategis 2018-2019 kementerian pariwisata, Jakarta: Kementerian Pariwisata.

Maryani (1997), Pengantar geografi pariwisata, Bandung: IKIP Bandung 
Pantin, D.A. \& Francis, J. (2005). Community based sustainable tourism, St. Augustine, Trinidad and Tobago: UWI-SEDU.

Sianipar, J.P.G, dan Entang, H.M., (2003), Teknikteknik analisis manajemen. Jakarta, LAN.

Suansri, Potjana (2003), Community-based tourism handbook, Thailand: REST Project

Yoeti, Oka A. (2008). Ekonomi pariwisata: introduksi, informasi, dan implementasi; Bambang Pribadi (ed.). Jakarta: Kompas Media Nusantara

\section{Jurnal/Proceeding/Skirpsi/Tesis/Disertasi}

Anuar, A. N. A., \& Sood, N. A. A. M., (2017). Community based tourism: understanding, benefits and challenges. Journal of Tourism and Hospitality, 6(1). DOI: 10.4172/21670269.1000263.

Goodwin, H., Santilli, R. (2009), Community-based tourism: a success, Leed: ICRT Occasional Paper 11.

\section{Sumber Online/Media Massa}

Kompas (2008), Kembangkan pariwisata berbasis masyarakat, Diakses pada 5 April 2020 dari https://nasional.kompas.com/read/2008/11/ 26/13425869/kembangkan.pariwisata.berba sis.masyarakat.

Kemenparekraf (2020), Data kunjungan wisatawan mancanegara bulanan tahun 2019, Diakses pada 15 Juni 2020 dari https://www.kemenparekraf.go.id/post/datakunjungan-wisatawan-mancanegarabulanan-tahun-2019.

Lestari, S. R., (2018), Serunya Barapan Kebo di
Festival Pesona Moyo 2018. Diakses pada 7 April $2020 \quad$ dari

https://travel.detik.com/travel-news/d4214252/serunya-barapan-kebo-di-festivalpesona-moyo-2018.

Mindtools, 2018, Force field analysis, Diakses pada 11 Juli $2019 \quad$ dari https://www.mindtools.com/pages/article/ne wTED 06. htm.

Nukman, H, (2019), Mengenal barapan kebo, tradisi unik di Sumbawa. Diakses pada 7 April 2020 dari https://travel.detik.com/domesticdestination/d-4581428/mengenal-barapankebo-tradisi-unik-di-sumbawa.

Paryati, E, (2019) Barapan kebo tradisi warisan leluhur khas Sumbawa. Diakses pada 7 April_2020_dari https://poskita.co/2019/12/12/barapankebo-tradisi-warisan-leluhur-khassumbawa.

Susanti, Apriliana (2017), Pariwisata berbasis masyarakat yang berkelanjutan: pariwisata oleh, dari dan untuk masyarakat, Diakses pada 4 April 2020 dari https://www.combine.or.id/article/Pariwisat a-Berbasis-Masyarakat-yangBerkelanjutan--Pariwisata-oleh-dari-danuntuk-Masyarakat_\%23_196.

\section{Peraturan Perundang-undangan}

\begin{tabular}{llrrr}
\hline UU RI Nomor 10 & Tahun & 2009 tentang \\
& Kepariwisataan, & JDIH & Kementerian \\
& Pariwisata RI Jakarta
\end{tabular}

